\title{
Forecasting Higher Education Enrollment In Egypt (2012-2016)
}

\author{
Dr. Yasser M. Gadallah* \\ Associate Professor of Economics \\ Director of Chinese-Egyptian Research Center \\ University of Helwan and Expert \\ In Strategic Planning Unit \\ Ministry of Higher Education, Egypt
}

\begin{abstract}
:
The objective of this study is to predict higher education enrollment in Egypt. Therefore, the paper provides a brief description of forecasting methods and its applications. Moreover, it reviews the available literature on the main determinants of higher education enrollment. To predict enrollment rate in Egypt for the period (2012-2016), it utilizes semi-log function and regression model using the available data from Ministry of Higher Education for the period (1991-2011). The main recommendation of this study is to encourage the private sector to involve in delivering the educational services through joining in partnerships with the government to establish new institutions or providing the private sector with the required licenses to establish new educational institutions based on the criteria which adopted by National Body for Quality and Accreditation.
\end{abstract}

\section{Introduction:}

Economists have long been interested in explaining determinants of higher education enrollment more than in developing models that forecast enrollment well. The majority of studies emphasize on status of higher education in the developed countries. The purpose of this paper is to predict higher education enrollment in Egypt. Section (1) shows an overview on the forecasting methods and the methodological differences among them, while section (2) discusses the determinants of higher education enrollment. In section (3) the results and analysis. Conclusions are reported in section (4).

\section{1- Forecasting Methods:}

The concept of forecasting refer to a technique or method to estimate, based on historical data, expectations, trends, and/or experience, a certain value of an uncontrollable variable for a certain period of time in the future. In addition, forecasting should consider some important factors such as the degree of competition in the market, political stability of the country, interest rates, inflation rates, exchange rates, and other factors. Forecasting methods or techniques can be classified into two broad groups, subjective and objective. Subjective methods do not consider the quantitative data. In contrast, objective methods are based on

\footnotetext{
* This paper is prepared based on a presentation delivered at the Egyptian Observatory for Education, Training and Employment Conference on Labor Market in Egypt and some Arab Countries: Current and Future which organized by The European Training Foundation (ETF), Italy and Information \& Decision Support Cabinet (IDSC), Marriott, Cairo, Egypt, November 2009.

This Research Was Submitted in December 2012, and Accepted for Publishing in March 2013.
} 
statistical data. Subjective methods are the usual mode when forecasting is a task and not a process (Carbone, 1999). In the following, these methods related to our study will be discussed with focusing on the objective ones. The objective methods require in generally quantitative data. They include two types: extrapolation models and data-based techniques as can be analyzed in the following:

\section{1-1- Extrapolation Models:}

Extrapolation models utilize historical data to make a forecasting. They are classified into four types: smoothing, quantitative analogies, neural networks and rule-based forecasting. Smoothing techniques represent the most popular and cost effective of the statistical extrapolation methods. Therefore, it will be spotlighted in the analysis. Smoothing techniques are used to reduce the random fluctuations in time series data to be smoothed.

Moving averages rank among the most popular techniques for the preprocessing of time series. They are used to filter random "white noise" from the data as can possible as, to make the time series more smoother than before. Whereas in moving averages the past or historical observations are weighted equally, Exponential Smoothing assigns exponentially decreasing weights as the observation get older.

In other words, recent observations are given relatively more weight in forecasting than the older observations. In the practice, double exponential smoothing is better at handling trends. Triple Exponential Smoothing is better at handling parabola trends. On the other hand, regression models and exponential smoothing do not impose any deterministic model to fit the series other than what is inherent in the time series itself.

\section{1-2- Data-based Techniques:}

The second type of the objective methods is so-called data-based techniques which include data mining and causal models. Data mining is a popular technique that uses complicated statistical analyses to identify relationships between the studied variables or factors. Data mining ignores theory and prior in searching for patterns. Notwithstanding ambitious claims and much research effort, a little bit of evidence shows that data mining technique provides benefits for forecasting. Keogh and Kasetty (2002) found insufficient evidence showing that data mining is useful. On the other hand, Causal models are based on prior knowledge and theory. Time-series regression and cross-sectional regression are commonly used for estimating model parameters of the equations. These models allow to examine the impacts of marketing activity, such as a change in cost of studying (Tuition fees), as well as the key aspects of the labor market, thus providing information for contingency planning. To develop causal models, it seems to be required selecting the causal variables by using theory and prior knowledge, identifying the key variables, the direction of their effects, and any constraints. (Allen and Fildes, 2001).

Statisticians have developed complicated procedures and steps for analyzing how well models fit the historical data. Measures or criteria of fit (such as determinant factor $\mathrm{R}^{2}$ or the standard error of the estimate of the model) have little relationship with forecast accuracy (quality) and they should therefore be avoided. Instead, holdout data should be used to assess the predictive validity of a model. This conclusion is based on findings from many studies with time-series data (Armstrong, 2001c). Statistical fit does relate to forecast accuracy for crosssectional data, although the relationship is weak. 
Causal models are most useful only when (1) strong causal relationships are expected, (2) the direction of the relationship is known, (3) causal relationships are known or they can be estimated, (4) large changes are expected to occur in the causal variables over the forecast horizon, and finally changes in the causal variables can be accurately forecasted or controlled, especially with respect to their direction.

After clarifying the different methods of forecasting in brief, there is an important question need to be answered. Which one of these methods can be the best? Generally speaking, selecting the best forecasting method for any particular situation is not a simple task and sometimes more than one method or technique may be the appropriate. Armstrong \& Green (2006), develop a benefit scheme for selecting methods as in the following.

The analyst should consider whether the data are sufficient to carry out the quantitative analysis (objective methods). If not, subjective methods are the alternative. Both of the methods can be used in some cases. If one has an enough time-series data, the analyst should determine whether there is knowledge about what empirical relationships might exist. In case of empirical knowledge of relationships is available, the causal models will be exploited. For time-series situations where one lacks causal knowledge, extrapolation is the appropriate technique. In case of no prior knowledge about relationships, but domain knowledge exists (if a forecaster knows that number of enrollment students will increase in information technology discipline for instance as a result to higher demand for graduates of information technology in the labor market), rule-based forecasting is the best technique in this case.

\section{2- Enrollment Rates' Forecasting: A Literature Review:}

Most of the prior studies on enrollment rates exploit the objective methods based on developing econometrics and trend models. The econometric models attempt to identify the determinants of enrollment rates. Once these have been identified, forecast values of the explanatory variables can be included in the regression equation to produce predicted values of the enrollment rates. Predicted values of the enrollment rates are then multiplied by the age-specific population projections (18-23 for higher education for example) to get the total enrollment projections. The econometric models can also produce prediction intervals that give the policy maker a sense of the uncertainty of the enrollment rate forecast. Consequently, they did not give numerical enrollment forecasts or prediction intervals.

With respect to the trend models, the forecasts are based on extrapolations of recent trends for different groups, and some educated guesses about future conditions as well (Centra, 1980). The models can be statistical trend fitting models or can be based on expert judgment as to future rates of change. Statistical trend fitting models have not been studied worldwide in the context of enrollment forecasting, particularly their forecast accuracy. In the following, we will briefly clarify the key determinants of higher education enrollment according to the literature review.

Traditional human capital models summarize the main determinants of higher education enrollment in three variables: the expected returns to this type of education (positive effect), ${ }^{1}$ the costs of studying or tuition fees (negative effect) and the income of the student's family (positive effect). However, several studies exploit time series data, most at a high level of 
aggregation across both student and educational institution types, e.g. Campbell and Siegel (1967) and Hight (1975) studies. Peltzman (1972), McPherson (1974) and Hopkins (1974) employ cross-section data for states of USA on the aggregate level. On the other hand, there have been evidences reflecting the influence of variation in unemployment rates as main determinant on enrollment behavior. One would expect some positive and some negative influence of unemployment on enrollment rates: higher unemployment reduces the opportunity cost of higher education enrollment while increases the difficulties of financing at the same time.

Forecasting models consider the variables that have significant variation over the forecasting period and can forecast well. The main examples of these variables are tuitions fees and unemployment rates. Other studies use each of cohort size and marriage rates as explanatory variables (independent variables) of higher education enrollment. It is because they may influence the underlying structural forces affecting enrollment determination. Moreover, they can be relatively easy to observe and forecast. Generally speaking, the most of these models had concentrated on enrollment determinants than on producing accurate forecasts or they ignore the quality of forecasting.

\section{3- Higher Education in Egypt, Status Quo and Forecasting:}

\section{3-1- The Status Quo:}

Unfortunately, it is rare studies handled determinants of higher education enrollment in Egypt using econometric models. This can be justified in different aspects. Firstly, the education in Egypt is free from basic to higher education according the Egyptian constitution except small ratio of the enrolled students in the private higher education. Therefore, this study will not consider the cost, finance or even the family's income variables. Secondly, the main determinant of higher education enrollment is the total marks earned by of student in the last year of secondary (high) school, which so-called Thanaweya Amma that reflect the mismatching between the education sector and labor market. Or in other words, the enrollment in different disciplines in higher education institutions does not rely on the market labour needs or trends. Last but not least, the gender issue does not represent a point of conflict if we take the ratio of enrolled female in higher education into account. It reaches roughly $46.5 \%$ in 2009/2010 out of the total enrolled students.

Since 2000, the Egyptian government is facing many challenges in all fields, particularly the higher education at each of domestic and international levels. As far as the domestic challenges, higher education enrollment rate is relatively small. It reaches about $29.6 \%$ in 2009/2010 against more than 50\% in USA, Australia, Canada, Argentina and countries of Europe, East Europe, Russia and Libya. On the other hand, this rate exceeds $30 \%$ in South Korea and some countries in Latin America, East Europe and Middle Asia. The growing flows of students coming from the secondary schools and the increasing desire of Egyptians in obtaining higher education represent big domestic issues. Accordingly, the financial problems will be exacerbated taking into account the requirement of quality assurance and accreditation in education especially the National Authority for Quality Assurance and Accreditation of Education NAQAAE has been established in 2007 to be responsible for the quality issue.

On the other hand, the international challenges come from different trends, for example, the liberalization and internationalization of higher education worldwide under the General 
Agreement on Trade in Services (GATS) (Ministry of Higher Education, 2007). Moreover, the shift toward a knowledge-based economy which reflects increasing the economic value of competencies (knowledge, attitudes, and skills) traditionally associated with higher education. Thereby, this leads to an increased emphasis on the link between education and the economy and expectations for educational contributions to economic development and consequently, that shift constitutes a real challenge for the higher education in Egypt (El Sebai, 2006).

The higher education institutions in Egypt were taking number of actions to deal with these obstacles and challenges. For example, with respect to the finance issue as one of the main problems or difficulties, the state or public universities adopted some successful revenue diversification strategies to increase its financial resources. The following displays these strategies.

\section{Specialized Centers and Units in the State University:}

The universities established number of specialized centers and units in different fields to serve the community and to enhance the link with the industry. These centers provide consultations and scientific solutions for the problems which come from the society to deliver a good service for the community at reasonable fees and to increase the revenue's payoff of the university as a financial resource to cover its costs taking into account the Egyptian government's trend towards the financial autonomy of the state universities in the near future. Income generation by specialized centers and units come from:(1) collaboration with industry; (2) commercialization of intellectual property rights; (3) provision of continuing education to industrial employees; (4) access to laboratory and scientific equipment; (5) manufacturing intermediate industrial products.

\section{Open and Distance Education Programs:}

There are many state universities have introduced open education programs to give the opportunity for some people to fulfill their academic education. In 2006/2007, 78\% out of the total enrolled students concentrated in Cairo University, followed by $15 \%$ \& $4 \%$ in Ain-Shams and Alexandria universities respectively (see figure1). By 2009/2010, Figure 2 shows that there are some of other state universities entered the open and distance education's market which lead to crowding for the pioneer universities. For example, the market share of Cairo University declined to be 46\% against increase in Ain-Shams University's market share to be 19\% in 2009/2010. New universities entered this market e.g., Assuit, Tanta, Menya...etc as can be seen in figure 2.

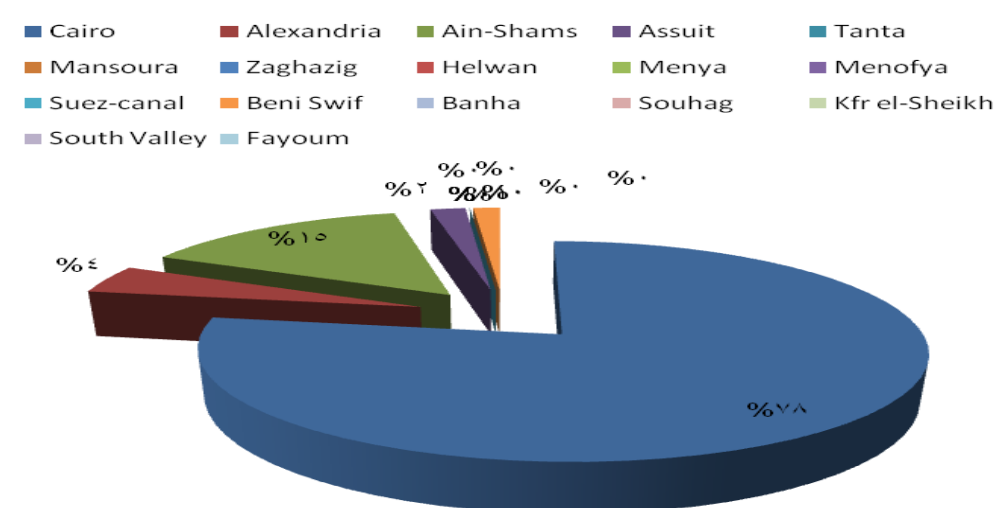

Source: Data of the figure collected from Strategic Planning Unit database, Ministry of Higher Education, Egypt.

Figure 1: Distribution of Open \& Distance Education Students by University (2006/2007) 


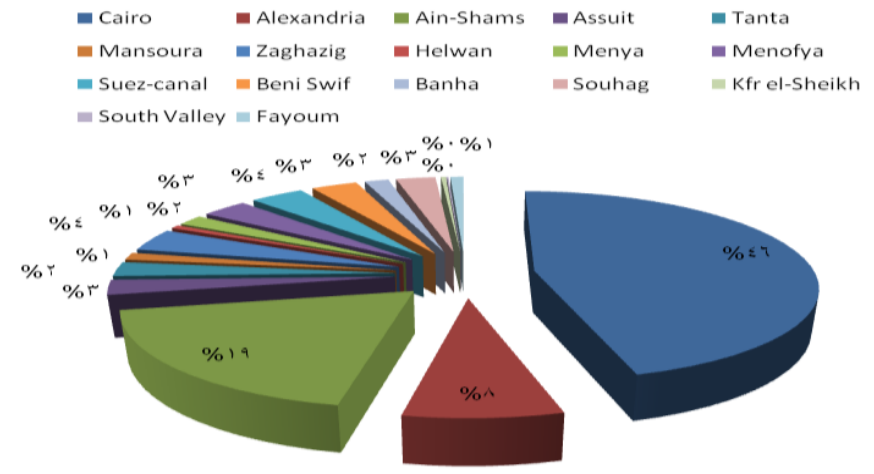

Source: Data of the figure collected from Strategic Planning Unit database, Ministry of Higher Education, Egypt.

\section{Figure 2: Distribution of Open \& Distance Education Students by University (2009/2010)}

Table 1 shows that total number of enrolled students in open and distance programs in all the state universities increased by $22.1 \%$ growth rate from 55974 to 135594 between 2006/2007 and 2009/2010. Also, the main dominant universities in this type of education were Cairo, Alexandria, Ain-Shams, Suez-canal universities. In the 2009/2010 academic year, about fourteen state universities among 18 deliver open and distance education.

Table 1

Number of Enrolled Students in Open \& Distance Education by University (2006/2007-2009/2010)

\begin{tabular}{l|c|c}
\hline \hline \multicolumn{1}{c|}{ University } & $\mathbf{2 0 0 6 / 2 0 0 7}$ & $\mathbf{2 0 0 9 / 2 0 1 0}$ \\
\hline \hline Cairo & 43417 & 61748 \\
\hline Alexandria & 2439 & 10270 \\
\hline Ain-Shams & 8234 & 25576 \\
\hline Assuit & 1072 & 3412 \\
\hline Tanta & 0 & 3296 \\
\hline Mansoura & 0 & 1692 \\
\hline Zaghazig & 0 & 5175 \\
\hline Helwan & 0 & 850 \\
\hline Menya & 0 & 2457 \\
\hline Menofya & 0 & 4251 \\
\hline Suez-canal & 0 & 4959 \\
\hline Beni Swif & 812 & 4257 \\
\hline Banha & 0 & 2197 \\
\hline Souhag & 0 & 3643 \\
\hline Kfr el-Sheikh & 0 & 435 \\
\hline South Valley & 0 & 182 \\
\hline Fayoum $\quad 0$ & 1194 \\
\hline \hline \multicolumn{1}{c}{ Growth Rate } & $\mathbf{5 5 9 7 4}$ & $\mathbf{1 3 5 5 9 4}$ \\
\hline \hline
\end{tabular}

Source: Strategic Planning Unit database, Ministry of Higher Education, Egypt.

Number zero in the table means that the program does not start in that year.

Most of these programs focus on some discipline such as commerce, arts, law, agriculture, mass communication and social work. Or in other words, most of them fall in the humanities and social sciences fields. Accordingly, it is critically to know the distribution of students in this type of education according to the programs or disciplines in the different 
المجلة العربية للإدارة، مج 34، ع 2 - ديسمبر (كانون أول) 2014

universities. In 2006/2007, the market share seems to be highly concentrated in commerce $76 \%$ followed by mass communication $10 \%$ and arts $10 \%$. Notwithstanding the increase in the absolute figure of enrolled students in commerce programs from 42421 to 86695 between $2006 / 2007$ and 2009/2010 (see table 2), there is a decline in its market share to be $64 \%$ (see figure 4). Law and arts programs take a place in the market in 2009/2010 to be the second and third ones after the commerce programs by $14 \%$ and $9 \%$ respectively crowding the mass communication to the forth rank by $7 \%$.

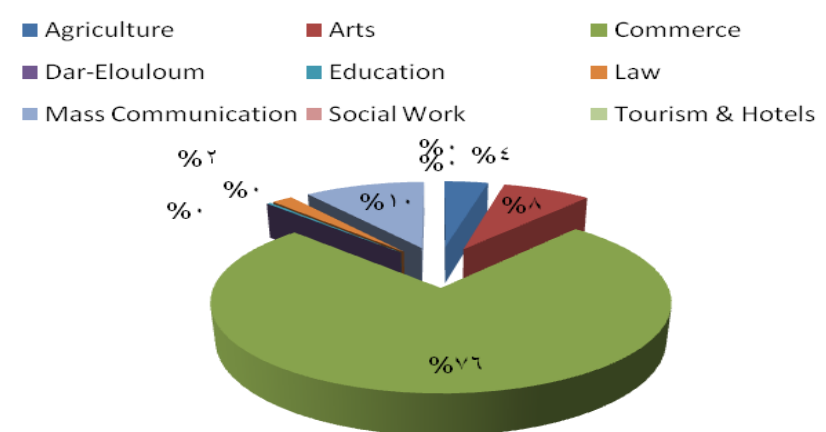

Source: Data of the figure collected from Strategic Planning Unit database, Ministry of Higher Education, Egypt.

Figure 3: Distribution of Open \& Distance Education Students by Discipline (2006/2007)

Table 2

Number of Enrolled Students in Open \& Distance Education by Discipline (2006/2007-2009/2010)

\begin{tabular}{l|c|c}
\hline \multicolumn{1}{c|}{ Discipline } & $\mathbf{2 0 0 6 / 2 0 0 7}$ & $\mathbf{2 0 0 9 / 2 0 1 0}$ \\
\hline \hline Agriculture & 2138 & 3817 \\
\hline Arts & 4328 & 12530 \\
\hline Commerce & 42421 & 86695 \\
\hline Dar-Elouloum & 0 & 1675 \\
\hline Education & 187 & 574 \\
\hline Law & 1024 & 19346 \\
\hline Mass Communication & 5876 & 9533 \\
\hline Social Work & 0 & 1051 \\
\hline Tourism \& Hotels $\quad$ Total & 0 & 373 \\
\hline \multicolumn{2}{c|}{} \\
\hline \hline
\end{tabular}

Source: Strategic Planning Unit database, Ministry of Higher Education, Egypt.

Number zero in the table means that the program does not start in that year.

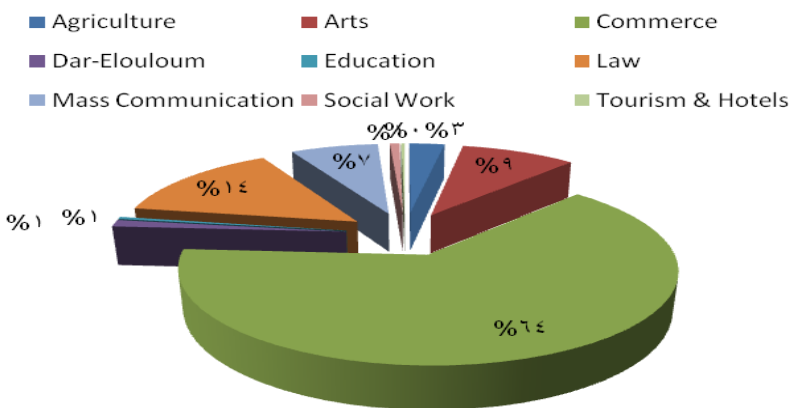

Source: Data of the figure collected from Strategic Planning Unit database, Ministry of Higher Education, Egypt.

Figure 4: Distribution of Open \& Distance Education Students by Discipline (2009/2010) 


\section{Non-traditional or New Academic Programs in Foreign Language}

State universities have provided new programs in foreign languages for which they charge tuition. Some state universities charge roughly annually LE7000 as tuition for a degree program in Commerce which uses English as a medium of instruction. The number of applicants in some degree programs in public universities exceeds the available spaces, a phenomenon which gives room for universities to charge tuition. While the tuition charged in this case is still only about $33 \%$ of the actual cost of the program, this arrangement sets a precedent towards cost recovery in public institutions (World Bank, 2002, p.40).

Based on a recent statistics, table 3 shows that the concentration degree (in figures) of the non-traditional programs can be appeared in Cairo (14), Ain- Shams (11), Alexandria (10) and Helwan (5) Universities. The total number of enrolled students in the new programs grow by $41 \%$ from 2118 to 10909 between 2006/2007 and 2009/2010. About 67\% of total students can be found in Cairo 2730, Alexandria 2360, Ain-shams 1210 and 1020 in Helwan universities (see figure 5). As can be seen in figures 6-9, four new programs intensively spread in the universities: Clinical pharmacy, communication \& computers, Malaysian medicine and petrochemical. These types of programs reflect the change of society's needs based on the radical movements all over the world. Actually, there are specific requirements to enroll in these programs which can be remarked in the limited numbers of student. The government encourages this type of education to fit the labor market needs.

Table 3

Number of New Programs and Students by University (2006/2007-2009/2010)

\begin{tabular}{c|c|c|c|c}
\hline \hline University & $\begin{array}{c}\text { Number of } \\
\text { Programs }\end{array}$ & $\mathbf{2 0 0 6 / 2 0 0 7}$ & $\mathbf{2 0 0 9 / 2 0 1 0}$ & Growth Rate \\
\hline \hline Ain-Shams & 11 & 109 & 1210 & 60.2 \\
\hline Alexandria & 10 & 354 & 2360 & 47.4 \\
\hline Assuit & 4 & 60 & 289 & 39.3 \\
\hline Banha & 2 & 34 & 136 & 34.7 \\
\hline Bini-Swiaf & 1 & 70 & 295 & 36.0 \\
\hline Cairo & 14 & 650 & 2730 & 35.9 \\
\hline Helwan & 5 & 267 & 1020 & 33.5 \\
\hline Mansoura & 3 & 135 & 906 & 47.6 \\
\hline Menofia & 2 & 16 & 115 & 49.3 \\
\hline Menya & 2 & 18 & 271 & 67.8 \\
\hline Souhag & 2 & $31 *$ & 94 & 27.7 \\
\hline Suz-Canal & 4 & 206 & 573 & 25.6 \\
\hline Tanta & 2 & 31 & 292 & 56.1 \\
\hline Zaghazig & 4 & $137 *$ & 618 & 37.7 \\
\hline Total & $\mathbf{6 6}$ & $\mathbf{2 1 1 8}$ & $\mathbf{1 0 9 0 9}$ & $\mathbf{4 1 . 0}$ \\
\hline \hline
\end{tabular}

Source: Data collected by Strategic Planning Unit, Ministry of Higher Education.

*2007/2008 data 


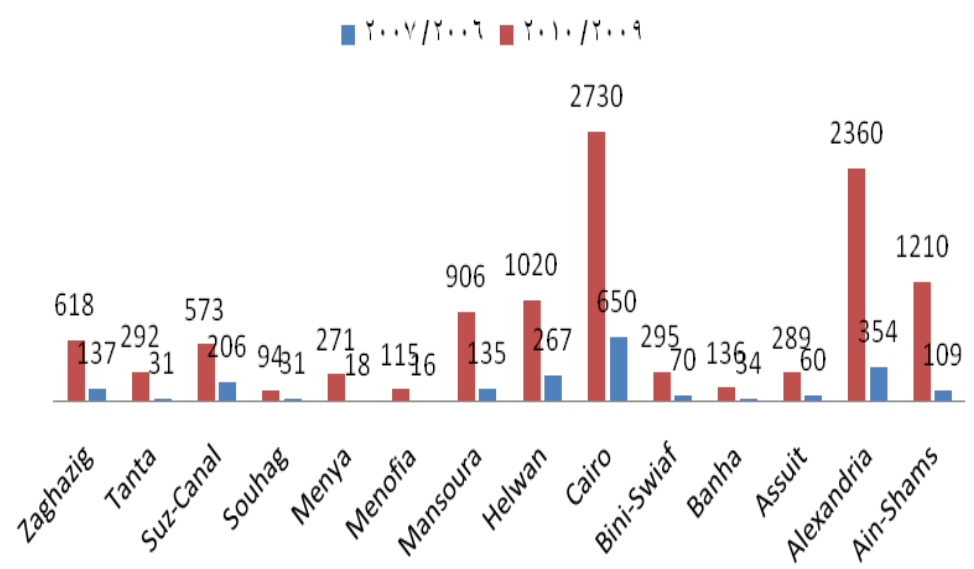

Source: Data of the figure collected from Strategic Planning Unit database, Ministry of Higher Education, Egypt.

Figure 5: Distribution of Students in the New Programs by University $(2006 / 2007-2009 / 2010)$

Figure 6 depicts the distribution of students in the clinical pharmacy program by the university. Cairo as the mother university in pharmacy comes in the first by $36 \%$ growth rate from 132 to 564 between 2006/2007 and 2009/2010. Bini-Swif University was in the second rank by $35.9 \%$ growth rate from 70 to 295 between 2006/2007 and 2009/2010. This result can be easily explained by considering that Bini-Swif was a branch affiliated to Cairo University. The other universities established clinical pharmacy to deliver distinctive educational services and based on a success stories in the pioneer universities. In figure 7, the distribution of students in the communication and computers by the university shows that Cairo, Alexandria and Ain-Shams universities consider the dominant supplier of this type of education among the universities. On other hand, the Malaysian medicine program firstly appears in Alexandria. The number of enrolled students in this program increases by $34.4 \%$ growth rate from 201 to 797 between 2006/2007 and 2009/2010 as can be seen in figure 8. As followers, Last but not least, petrochemical program shares by three universities in Egypt, Cairo, Alexandria and Suez-canal. Growing of enrolled students was very high in Cairo University by 59\% from 52 to 547 between 2006/2007 and 2009/2010. In the second position, Alexandria achieved $28.3 \%$ growth rate followed by Suez-canal by $26.8 \%$ growth rate (see figure 9).

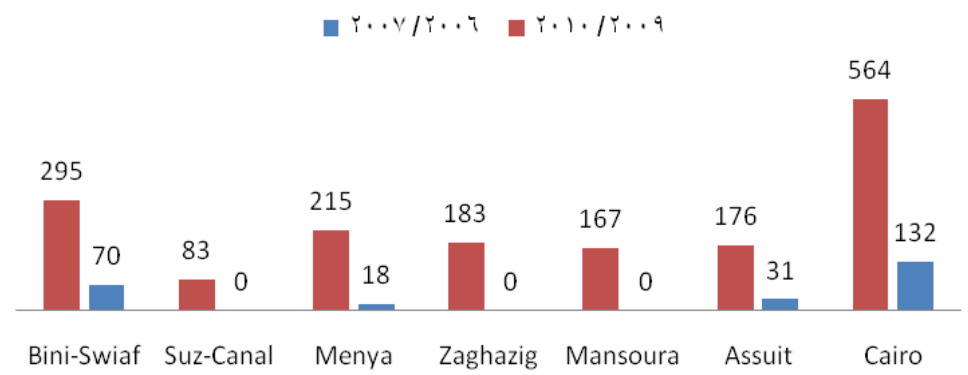

Source: Data of the figure collected from Strategic Planning Unit database, Ministry of Higher Education, Egypt.

Figure 6: Distribution of Students in the Clinical Pharmacy by University $(2006 / 2007-2009 / 2010)$ 

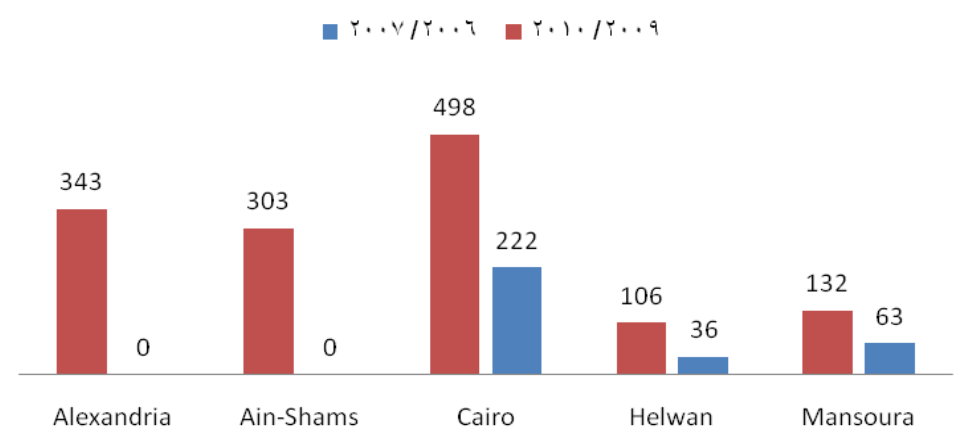

Source: Data of the figure collected from Strategic Planning Unit database, Ministry of Higher Education, Egypt.

Figure 7: Distribution of Students in Communications \& Computers by University (2006/2007- 2009/2010)

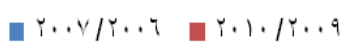

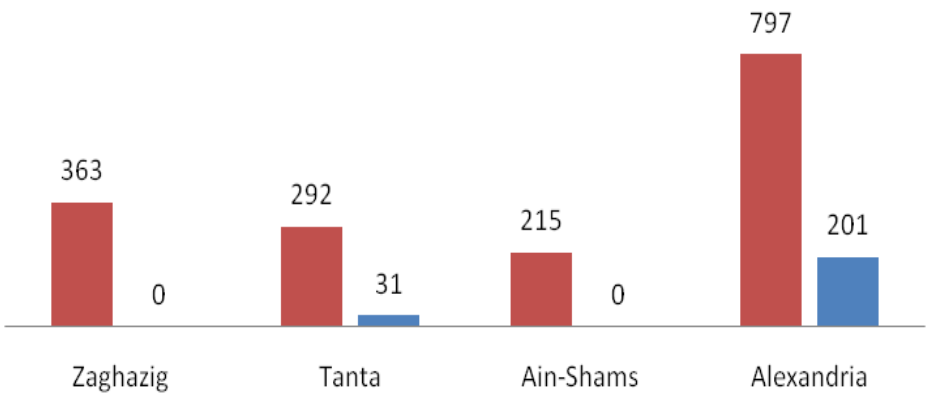

Source: Data of the figure collected from Strategic Planning Unit database, Ministry of Higher Education, Egypt.

Figure 8: Distributin of Students in Malaysian Medicine by University (2006/2007- 2009/2010)

$$
\square r+. v / r+r \quad \square r \cdot 1 \cdot / r \cdot \cdots 9
$$

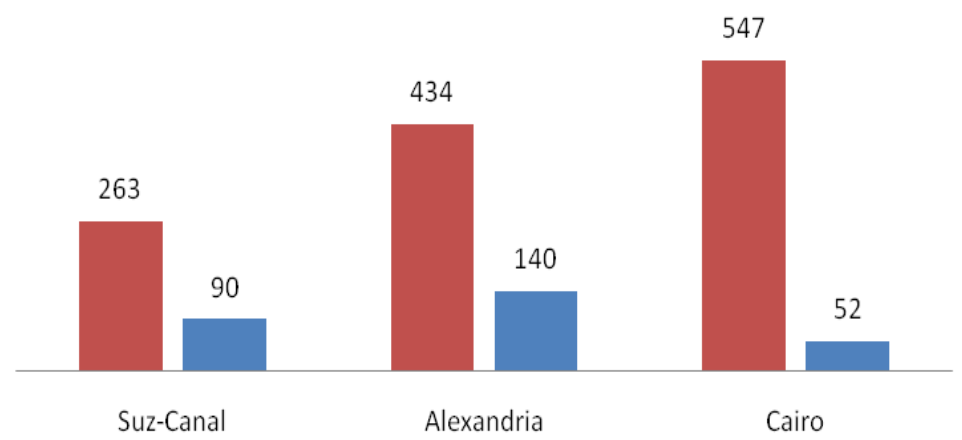

Source: Data of the figure collected from Strategic Planning Unit database, Ministry of Higher Education, Egypt.

Figure 9: Distribution of Students in Petrochemical by University (2006/2007-2009/2010) 
On the other side, private higher education has played a significance role in relieving the state from the burden of the financial resources for education. Considering the provision of general education, the private sector helps save a large amount of state budget for capital and operational costs. There are a relatively large number of private institutes and universities. The Council of Private Universities is given authority to supervise private universities under the Ministry of higher education. NAQAAE is responsible for rules and regulations needed to ensure the standards and accreditation of state and private higher education institutions. In the meantime, there is a rapid expansion of private higher education to satisfy the increase in the social demand for this level of education. However, financial resources of private higher institutions come only from tuition fees which are much higher than those of state institutions. It is thus vital for the state to provide additional support for private institutions to promote the role of the private sector in the educational provision and to relieve the government's from the burden of the educational financial resources.

\subsection{Data and Methodology:}

Due to the central policy by the Egyptian government to determine enrollment rates in higher education via central placement office, Higher education enrollment in Egypt is considered to be as an exogenous variable. Accordingly, the exploited methodology is to produce the forecasted higher education enrollment regresses on time using a semi-log function to get the predicted values of higher education enrollment. The predicted values of higher education enrollment are then divided by the population age group 18-23 projections of the Central Agency for Public Mobilisation and Statistics (CAPMAS) and it collected by Strategic Planning Unit at ministry of higher education in Egypt to obtain the enrollment rates projections. The data of higher education enrollment in the period (1991-2011) on the aggregate level comes from the Ministry of Higher Education. To test the accuracy of the forecasting, the study will use data in the period (1991-2007) to make a forecasting for the period (2008-2010) and calculate mean absolute of percentage error MAPE based on the actual and available data on this period and its forecasted values. According to the results of MAPE, we will utilize the full time series data (1991-2011) to make the forecasting for the period (2012/2016). The forecasting will include the total, female and male enrolled students exploiting EViews software.

\subsection{Results and Analysis:}

Utilizing time series data (1991-2007), total or gross higher education enrollment in the period (2008-2010) has forecasted based on a semi-log function as above shown. Table 4 summarizes the results of test of forecasting's accuracy using MAPE. The values of MAPE are $2.7 \%, 3.8 \%$ and $9.8 \%$ in 2008,2009 and 2010 respectively versus $5.4 \%$ in the whole period (2008-2010). These results seem to be reasonable and thereby, we can accept the quality of forecasting. Similar results are noticed concerning the forecasting of enrolled students either from male or female students. The values of MAPE as can shown in tables 5 \& 6 are $4.7 \%(0.6 \%), 2.9 \%$ (5\%) and 8.7\% (11.2) for male (Female) students in 2008, 2009 and 2010 respectively. Also, the values of MAPE in whole period are $5.4 \%$ for male versus $5.5 \%$ for female. Accordingly, the results of MAPE support the forecasting values of higher education enrollment at all levels: total, male and female data and then we will use the full time series data (1991-2010) to make a prediction for the period (2012-2016). 
Table 4

Forecasting's Quality of Gross Enrolled Students

\begin{tabular}{c|c|c|c|c}
\hline \hline Year & Actual & Forecasted & Error & MAPE \\
\hline \hline 2008 & $2,488,434$ & 2557810.5 & 69376.462 & 2.7 \\
\hline 2009 & $2,524,101$ & 2622443.1 & 98342.146 & 3.8 \\
\hline 2010 & $2,447,712$ & 2688712.7 & 241000.65 & 9.8 \\
\hline Sum & $\mathbf{7 , 4 6 0 , 2 4 7}$ & & $\mathbf{4 0 8 7 1 9 . 2 6}$ & $\mathbf{5 . 4}$ \\
\hline \hline
\end{tabular}

Source: The estimations and calculations have been done by the Author.

Table 5

Forecasting's Quality of Enrolled Male Students

\begin{tabular}{c|c|c|c|c}
\hline \hline Year & Actual & Forecasted & Error & MAPE \\
\hline \hline 2008 & $1,306,444$ & 1367898.6 & 61454.56 & $\mathbf{4 . 7}$ \\
\hline 2009 & $1,354,515$ & 1394280.6 & 39765.619 & $\mathbf{2 . 9}$ \\
\hline 2010 & $1,307,247$ & 1421126.1 & 113879.1 & $\mathbf{8 . 7}$ \\
\hline Sum & $\mathbf{3 , 9 6 8 , 2 0 6}$ & & $\mathbf{2 1 5 0 9 9 . 2 8}$ & $\mathbf{5 . 4}$ \\
\hline \hline
\end{tabular}

Source: The estimations and calculations have been done by the Author.

Table 6

Forecasting's Quality of Enrolled Female Students

\begin{tabular}{c|c|c|c|c}
\hline \hline Year & Actual & Forecasted & Error & MAPE \\
\hline \hline 2008 & $1,181,990$ & 1189900.1 & 7910.1102 & $\mathbf{0 . 6}$ \\
\hline 2009 & $1,169,586$ & 1228489.9 & 58903.941 & $\mathbf{5 . 0}$ \\
\hline 2010 & $1,140,465$ & 1268342.5 & 127877.51 & $\mathbf{1 1 . 2}$ \\
\hline Sum & $\mathbf{3 , 4 9 2 , 0 4 1}$ & & $\mathbf{1 9 4 6 9 1 . 5 6}$ & $\mathbf{5 . 5}$ \\
\hline \hline
\end{tabular}

Source: The estimations and calculations have been done by the Author.

Table 7 depicts the forecasting of higher education enrollment rates during the period (2012-2016). The forecasting of higher education enrollment in figures has been done using regression model based on the full data time series (1991-2011). The rates of enrollment are calculated by divide the forecasted higher education enrollment in figures by the projections of age group (18-23). ${ }^{1}$ Regarding the total enrollment rates, the forecasted rates refer to steady increase with it. It will be increased from $32.7 \%$ (2012) to $37.2 \%$ (2016). This result seems to be very important for the policy makers. The expected increase in higher education enrollment rate means the necessity to expand in establishing new educational institutions to absorb the expected increase in demand for higher education till 2016. For financial problems faced by the Egyptian government, it is recommended to encourage the private sector to involve in this process through entering into partnerships with the government to establish new institutions or to provide the private sector with the required licenses to establish new educational institutions based on the criteria which adopted by NAQAAE.

( $\left.{ }^{1}\right)$ These projections have been done by the Economic and Population Studies Department at Strategic Planning Unit. It based on final results of General Census of Population and Institutions published in 1996, annually growth rate of population from CAPMAS, Population expectation rates, population extrapolations based on spectrum program and life tables and Esbraj model for age groups. 
المجلة العربية للإدارة، مج 34، ع 2 - ديسمبر (كانون أول) 2014

Table 7

Higher Education Enrollment Rates by Gender (2012-2016)

\begin{tabular}{c|c|c|c}
\hline \hline Year & Male & Female & Total \\
\hline \hline 2012 & 33.9 & 30.2 & 32.7 \\
\hline 2013 & 34.7 & 31.1 & 33.7 \\
\hline 2014 & 35.6 & 32.1 & 34.8 \\
\hline 2015 & 36.6 & 33.2 & 36.0 \\
\hline 2016 & 37.5 & 34.3 & 37.2 \\
\hline \hline
\end{tabular}

Source: The estimations and calculations have been done by the Author.

\section{4- Conclusion:}

Forecasting methods can be classified into two broad groups, subjective and objective. Subjective methods are not data driven. In contrast, objective methods use data to generate a baseline forecast that becomes the point of reference in the process. On the other hand, the literature review shows that forecasting models draw attention to variables that have significant variation over the forecasting period and can forecast well. The main variables are costs of studying and unemployment rates. Some studies use each of cohort size and marriage rates as an explanatory variables of higher education enrollment, because they may influence the underlying structural forces affecting enrollment determination. Accordingly, the methodology of this study is to produce the forecasted higher education enrollment regresses on time using a semi-log function to get the predicted values of higher education enrollment for the period (2012-2016). The main recommendation of this study is to encourage the private sector to involve in delivering the educational services through entering in partnerships with the government to establish new institutions or to grant the private sector the required licenses to establish new educational institutions based on the criteria which adopted by NAQAAE. 


\section{References}

- Allen, P. G. and R. Fildes. (2001). "Econometric Forecasting", In: J. S. Armstrong (Ed.) Principles of Forecasting. Norwell, MA: Kluwer Academic Publishers, pp. 303-362.

- Armstrong J. (Ed.). (2001) Principles of Forecasting: A Handbook for Researchers and Practitioners, Kluwer Academic Publishers.

- Armstrong, J. S. (2001c). "Evaluating Forecasting Methods," In: J. S. Armstrong (Ed.) Principles of Forecasting. Norwell, MA: Kluwer Academic Publishers, pp. 365-382.

- Armstrong, J. S. and F. Collopy. (1993). "Causal Forces: Structuring Knowledge for Time Series Extrapolation", Journal of Forecasting, 12, 103-115.

- Armstrong, J. S. and F. Collopy. (1998). "Integration of Statistical Methods and Judgment for Time Series Forecasting: Principles from Empirical Research", In: G. Wright and P. Goodwin (Eds.), Forecasting with Judgment. Chichester: John Wiley.

- Armstrong, J. S.; M. Adya F. and F. Collopy. (2001) "Rule-based Forecasting: Using Judgment in Time-Series Extrapolation", In: J. S. Armstrong (Ed.) Principles of Forecasting. Norwell, MA: Kluwer Academic Publishers, pp. 259-282.

- Armstrong, J. S. and C. Green Kesten. (2006). "Demand Forecasting: Evidence-based Methods", A Chapter for the Forthcoming Book Strategic Marketing Management: A Business Process Approach, edited by Luiz Moutinho and Geoff Southern.

- Campbell, Robert and Barry Siegel. (1967) "The Demand for Higher Education in the United States, 1919-1964", American Economic Review, 57, pp. 482-494.

- Carbone, R. (1999). "THCMS Methodology for Evaluating the Forecasting Systems", Unpublished, July.

- Centra, John A. (1980). "College Enrollment in the 1980s: Projections and Possibilities," Journal of Higher Education, (51(1), 1980), pp. 19-38.

- El Sebai, N. M. (2006) "The Egyptian Higher Education System: Towards Better Quality in the Future”, Journal of Futures Studies, November 2006, 11(2), pp.75 - 92.

- Hight, John. (1975). "The Demand for Higher Education in the U.S. 1927-72: The Public and Private Institutions", Journal of Human Resources, 10, pp.512-520.

- Hopkins, Thomas D. (1974). Higher Education Enrollment Demand, Unpublished Ph.D. Dissertation, Yale University.

- Keogh, Eamonn and Shruti Kasetty. (2002). "On the Need for Time Series Data Mining Benchmarks: A Survey and Empirical Demonstration", Proceedings of the Eighth ACM SIGKDD International Conference on Knowledge Discovery and Data Mining.

- McPherson, Michael S. (1974). The Demand for Public and Private Higher Education, Unpublished Ph. D. Dissertation, University of Chicago.

- Ministry of Higher Education, Master Plan for Higher Education in Egypt (2007-2022). 2007.

- Peltzman, Sam. (1972) "The Effect of Government Subsidies-in-Kind on Private Expenditures: The Case of Higher Education”, Journal of Political Economy, 81, January/February, pp. 1-27.

- World Bank. (2002). Arab Republic of Egypt Higher Education Enhancement Project (HEEP). Washington, D.C.: World Bank. 